\title{
Magnetic Susceptibility Measurements on Fly Ash Admixtured Cement Hydrated with Groundwater and Seawater
}

\author{
R. Gopalakrishnan,", , S. Barathan ${ }^{2}$, D. Govindarajan ${ }^{2}$, \\ ${ }^{1}$ Department of Physics, SRM University, Kattankulathur -603 203. Tamilnadu, India \\ ${ }^{2}$ Department of Physics, Annamalai University, Annamalai Nagar, 608 002, Tamilnadu, India
}

\begin{abstract}
The present works reports the effect of Flyash on the properties of Portland cement hydrated with ground water and seawater through magnetic susceptibility study. Cement pastes containing $0,10,20,30 \%$ replacement of flyash with cement and in a Water cement ratio (W/C) ratio of 0.4 have been prepared. The magnetic susceptibility at different hydration ages has been determined by Faraday Curie balance method and this has been correlated to changes in setting time and compressive strength measurement. The observed result shows that, irrespective of water the magnetic susceptibility increases with increasing flyash percentage replacement level in cement.
\end{abstract}

Keywords Magnetic susceptibility, Cement, Fly ash, Setting time, Seawater.

Cement nomenclature:

$\mathrm{C}=\mathrm{CaO} ; \mathrm{S}=\mathrm{SiO}_{2} ; \mathrm{H}=\mathrm{H}_{2} \mathrm{O} ; \mathrm{C}_{3} \mathrm{~S}=3 \mathrm{CaO} . \mathrm{SiO}_{2} ; \mathrm{C}_{2} \mathrm{~S}=$

$2 \mathrm{CaO} . \mathrm{SiO}_{2} ; \mathrm{C}_{3} \mathrm{~A}=3 \mathrm{CaO} . \mathrm{Al}_{2} \mathrm{O}_{3}$

$\mathrm{C}_{4} \mathrm{AF}=4 \mathrm{CaO} \cdot \mathrm{Al}_{2} \mathrm{O}_{3} \cdot \mathrm{Fe}_{2} \mathrm{O}_{3} ; \mathrm{CH}=\mathrm{Ca}(\mathrm{OH})_{2}$

\section{Introduction}

Flyash is generated in a power plant that uses bituminous and anthracite coal as a power source. The amorphous $\mathrm{SiO}_{2}$ content of this ash is high and it can be accepted as a pozzolanic material. Flyash is finer than Portland cement. It is known that fine pozzolans improve the properties of cement based materials due to their pozzolanic properties and filler effect. Reuse of flyash has been widely promoted and applied in many engineering applications and it offers cost reduction, energy savings, superior quality and also one way to reduce green house effect and global warming.

The hydration mechanism of cement and mineral admixtured cement using X-ray diffraction analysis, Scanning electron microscopy, Differential thermal analysis, Fourier transform infrared spectroscopy, Nuclear magnetic resonance and Dielectric measurements was explained by number of authors' [1-6].

During hydration of cement, the reaction products vary with time from one phase to another. The magnetic constituents of Portland cement and/or the reaction productsacquire magnetic properties due to their alignment with the

* Corresponding author:

gopalsrmphysics@gmail.com (R. Gopalakrishnan)

Published online at http://journal.sapub.org/materials

Copyright (C) 2011 Scientific \& Academic Publishing. All Rights Reserved external field and there is every possibility of change in susceptibility. Susceptibility $(\chi)$ measurements are used to detect the solubility limit of iron in different forms in $\mathrm{C}_{3} \mathrm{~A}[7]$. Beata J. Goluchowska[8] reported magnetic susceptibility of cement dusts depends on the iron content in raw materials, additives and fuels introduced into the kilns in which clinker in backed. According to David et al,[9] clay minerals have higher amount of oxides and hence this factor enhanced the susceptibility values. The magnetic susceptibility is an important physical property and it gives the analysis and/or chemical properties of cementitious materials. The magnetic susceptibility measurements of different water on cement hydration were studied by Govindarajan[10] with the help of Faraday Curie balance. They have reported that the cement mixing with distilled water has the highest value of susceptibility and then groundwater and then seawater.

In India, due to the climate change and natural calamities (floods, delay of monsoon, tsunami and earthquake etc.,) the potable water quality and the availability of potable water are scarce commodity. Under these circumstances using other alternatives like rain water, river water and one of the natural potential i.e., seawater can also be think off, provided it is harmless.

The influence of different waters on cement hydration was studied by Barathan et al.,[11] with the help of X-band Microwave technique. They have reported that the cement mixing with seawater has the highest value of dielectric constant $(\varepsilon)$ and conductivity $(\sigma)$ and then groundwater and then distilled water. According to Manu Santhanam et al.,[12] the high Chloride concentration of seawater could have played an important role by binding the $\mathrm{C}_{3} \mathrm{~A}$ to form 
chloroaluminated compounds, such as Friedel's salt and also by lowering the expansive potential of ettringite.

To the knowledge of authors', no magnetic susceptibility studies have been reported so far on hydration of cement admixtured with fly ash treated groundwater and seawater at different hydration periods. Several magnetic methods are available for measuring magnetic susceptibility but Faraday-Curie balance is very sensitive and suitable method to measure susceptibility of even a very small quantity of sample. In the present study, the authors' present magnetic susceptibility measurements on cement and fly ash admixtured cement paste hydrated with groundwater and seawater at different hydrated time duration using Faraday-Curie balance available in Material Science Laboratory, Department of Physics, Annamalai University, Tamilnadu, India.

\section{Materials and Methods}

Fly ash and Ordinary Portland cement (OPC) were commercial one. The percentages of oxides in the Ordinary Portland cement was found out to be $\mathrm{CaO} ; 63.32, \mathrm{SiO}_{2}$; 21.70, $\mathrm{Al}_{2} \mathrm{O}_{3} ; 5.40, \mathrm{Fe}_{2} \mathrm{O}_{3} ; 3.40, \mathrm{MgO} ; 2.69, \mathrm{SO}_{3} ; 2.70$ and Loss on ignition was 0.79 . The percentages of oxides in the flyash was found out to be $\mathrm{CaO} ; 1.95, \mathrm{SiO}_{2} ; 49.02, \mathrm{Al}_{2} \mathrm{O}_{3}$; 32.03, $\mathrm{Fe}_{2} \mathrm{O}_{3} ; 7.14, \mathrm{MgO} ; 1.7, \mathrm{SO}_{3} ; 1.2$ and Loss on ignition was 1.58 . The ground water $(\mathrm{GW})$ and sea water $(\mathrm{SW})$ were analysed using standard procedure recommended by Tamilnadu Water Supply and Drainage Board, Cuddalore, Tamilnadu, India (Table 1).

\subsection{Preparation of Samples for Susceptibility Measurements}

The samples were used in the received form without any further modification. Groundwater and seawater were used for the preparation of the cement paste. The water-cement (W/C) ratio was 0.4 for all the samples. 10 grams of ordinary Portland cement was weighed and $4 \mathrm{cc}$ of water was added to the cement, so that the water cement ratio is 0.4 and made to a paste by gentle mixing. The flyash (FA) was mixed in the proportion of 10, 15, 20, 25 and 35 weight percent of Portland cement samples. Sample was then hydrated for various times. The hydration reaction was stopped at necessary different time duration like $1 / 2 \mathrm{hr}, 1$ hour, 2 hours, 4 hours, 6 hours, 1 day, 2 days, 4 days, 1 week, 2 weeks and 4 weeks by using acetone[13]. The solids were then allowed to dry in air to complete evaporation of the acetone. The dried solids were then oven dried at $110{ }^{\circ} \mathrm{C}$ for 1 hour to remove the free or evaporable water. The dried samples were powdered using agate mortar. All the samples were ground for $1 / 2$ hour and the grain size was maintained even. Finally the samples were stored in a dessicater. The powdered samples were weighed and then filled up in the capsule tightly. The sample was allowed to the sample holder and was used as the specimen for the curie balance. This procedure was repeated for different hydrated sample and hydrated to a time duration of $1 / 2$ hour, 1 hour, 2 hours, 4 hours, 6 hours, 1 day, 2 days, 4 days, 1 week, 2 weeks and 4 weeks.

\subsection{Setting Time and Compressive Strength Measurements}

Setting time, Compressive strength were measured on fly ash admixtured cement $(0,10,15,20,25$ and $35 \mathrm{wt} \%)$ in a water to cement ratio of 0.4 treated with groundwater and sea water. Setting time was measured using a Vicat apparatus and the compressive strength were determined using Compression Testing Machine (Techno- Science Trading Corporation, New Delhi, India) set up available in Department of Structural Engineering, Annamalai University, India, and using standard procedure[14] and shown in Table 2.

Table 1. Content of solvents of seawater and groundwater $(\mu \mathrm{g} / \mathrm{g})$

\begin{tabular}{cccccccc}
\hline Water & Total dissolved solvents & Total hardness & Chlorine & Magnesium & Calcium & Sulphur & Sodium \\
Seawater & 30500 & 1060 & 16400 & 1080 & 272 & 5.80 & 9100 \\
Groundwater & 1600 & 170 & 70 & 20 & 68 & 2.50 & 155 \\
\hline
\end{tabular}

Table 2. Setting time, Compressive strength of flyash admixtured cement treated with groundwater and seawater

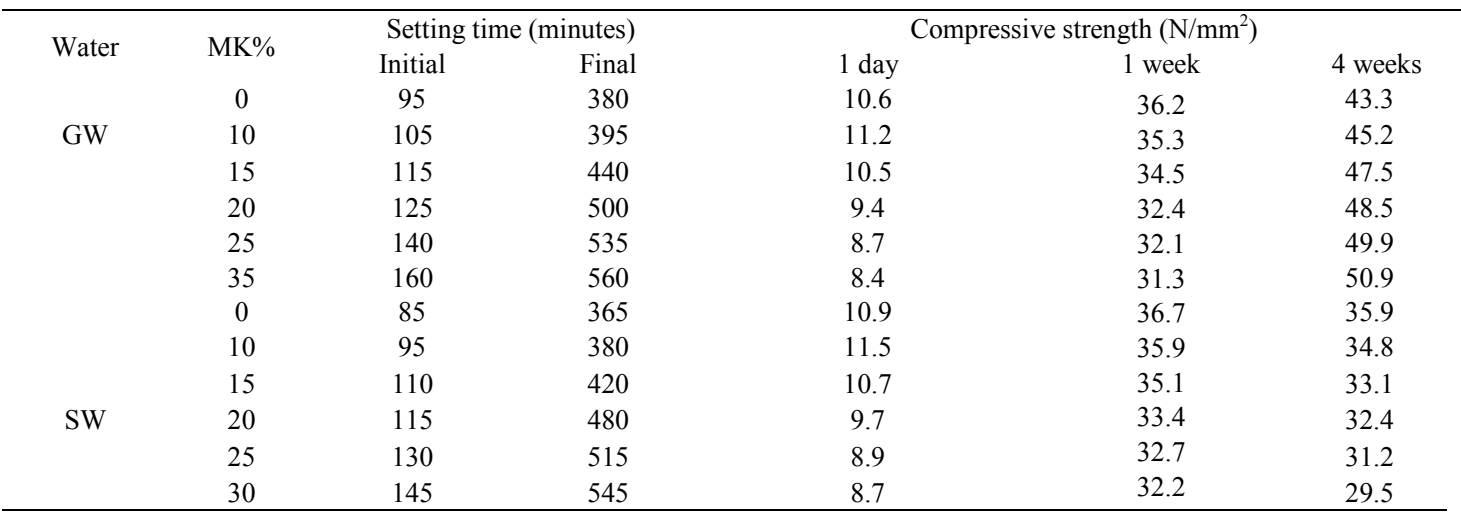




\subsection{Experimental details for susceptibility measure- ments}

Fig 1. Shows the Faraday-Curie balance along with Heyding's type pole pieces[15].

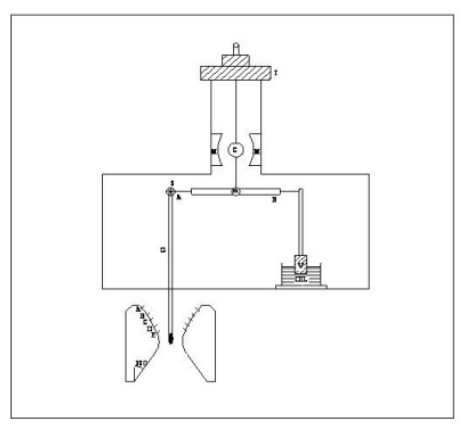

Figure 1. Faraday Curie balance

It consists of a light aluminium beam (AB) of length 25 $\mathrm{cm}$ suspended by means of a fine copper wire and its upper end is soldered to a torsion head (T). The sample holder was connected to the lower end of the glass tube $(\mathrm{G})$ suspended from the left end of aluminium beam. A small mirror (m) was attached at the center of the beam. A circular scale (S) graduated in degrees provided at the upper end of the glass tube facilitates the rotation of the sample from $0^{\circ}$ to $360^{\circ}$. The right end of the arm carries a damping vane $(\mathrm{V})$ made of aluminium and was dipped in a dash-pot of light viscous oil. This arrangement effectively damps out all spurious vibration. Above the aluminium beam there is a balancing coil $(\mathrm{C})$ comprising of 500 turns of copper wire wound over a hollow rectangular frame. The powerful horse shoe shaped permanent magnet (MM) produce a strong radial field encloses the coil ' $C$ '. The coil moving in the radial field constitutes a galvanometer. By passing a suitable current through the coil using potential divider arrangement, the deflection can be nullified. A digital millevoltmeter measures the current flowing in the balancing coil and directly displays the value in terms of voltage[16].

Curie balance has to be calibrated for various samples of known susceptibility value (Fig. 2). The sample in powder form is filled in sample holder and was suspended in the predetermined region where magnetic force is uniform and maximum. When the magnetic field was switched on, the sample experiences a magnetic force. This produces a deflection of the beam and the deflection is noted by mirror $(\mathrm{m})$ and the lamp and scale arrangement. The force exerted on the sample was counter-balanced passing a suitable current, by adjusting the resistance in the potential divider arrangement and hence the voltage required to compensate the magnetic force on the sample was noted. The sample was rotated in steps of $20^{\circ}$ and at each position the procedure was repeated and finally the average annulling voltage Vs is calculated. The experiment was repeated for empty sample holder to determine its annulling voltage $\mathrm{V}_{\mathrm{O}}$. The difference of voltage $\left(\mathrm{V}_{\mathrm{S}}-\mathrm{V}_{\mathrm{O}}\right)$ was a measure of annulling voltage for the sample. The calibration graph (Fig. 2) was drawn between the known susceptibility value of different samples $\left(\mathrm{K}_{2} \mathrm{Cr}_{2} \mathrm{O}_{7}, \mathrm{NiSO}_{4}\right.$,
$\mathrm{CaSO}_{4} .7 \mathrm{H}_{2} \mathrm{O}, \quad \mathrm{FeSO}_{4} \cdot 7 \mathrm{H}_{2} \mathrm{O}, \quad \mathrm{MnSO}_{4}, \mathrm{Gd}_{2} \mathrm{O}_{3}, \quad \mathrm{Fe}(\mathrm{OH})_{3}$, $\mathrm{HOCl}_{3}, \mathrm{Er}_{2} \mathrm{O}_{3}$ ) and the corresponding annulling voltage per unit mass.

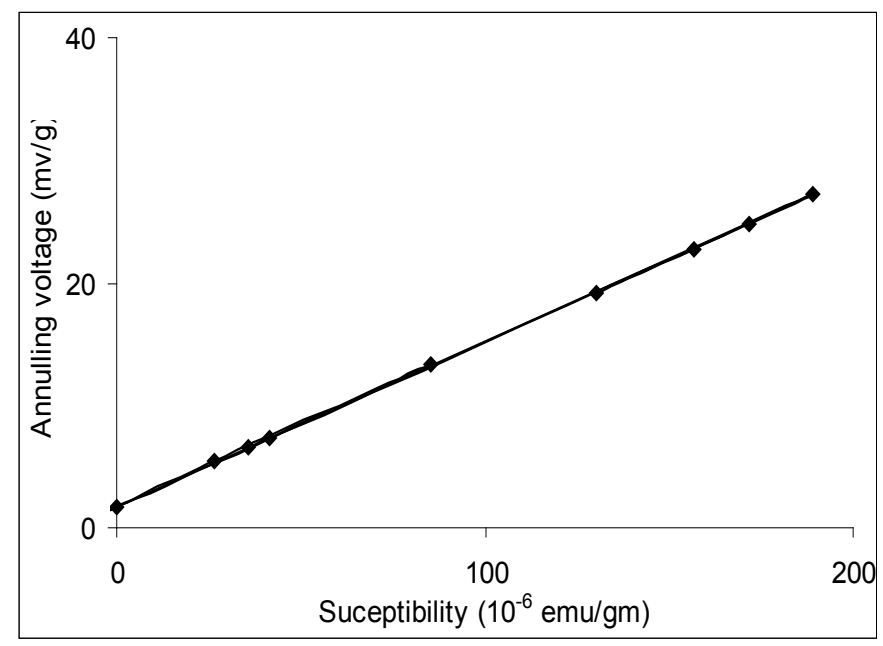

Figure 2. Calibration graph

The magnetic susceptibility of different time duration of hydrated cement was obtained from the calibration graph, by measuring the annulling voltage. The sensitivity of the instrument is \pm 0.001 . All the measurements were taken at $28 \pm$ $2^{\circ} \mathrm{C}$

\section{Results and Discussion}

The susceptibility value of the anhydrous cement was observed to be $91.028 \times 10^{-6} \mathrm{emu} / \mathrm{gm}$. This value $\chi>0$ indicates the cement samples are paramagnetic. The positive paramagnetic susceptibility of the anhydrous cement may be considered as a resultant of the contribution from all the impurity ions and especially $\mathrm{Fe}_{2} \mathrm{O}_{3}$ contained in $\mathrm{C}_{3} \mathrm{~A}$ and $\mathrm{C}_{4} \mathrm{AF}$ phases[17]. Graphs are drawn between the observed susceptibility values and different hydrated time duration for cement and flyash admixture cement treated with GW (Fig 3) and SW (Fig 4) in a non-uniform scale.

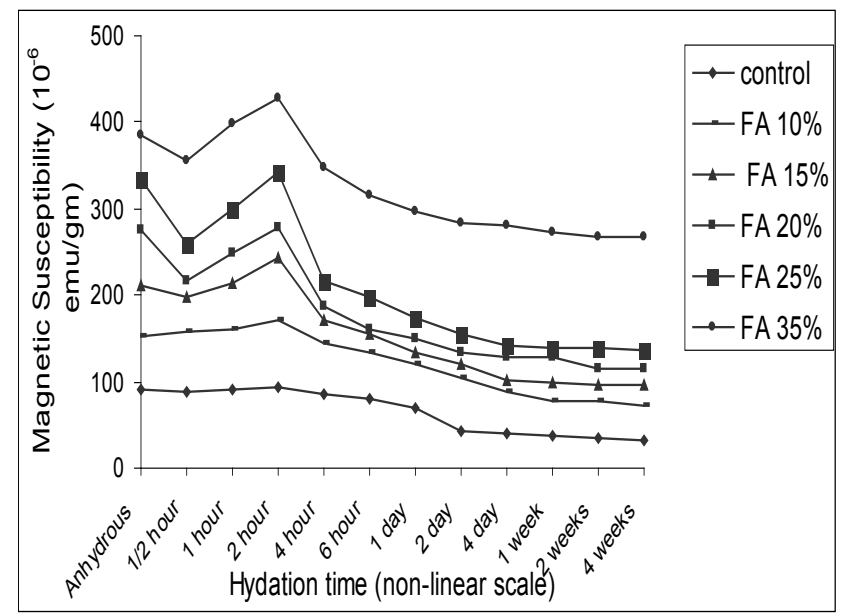

Figure 3. Magnetic susceptibility $v s$. Different hydration time duration of flyash admixtured cement paste treated with groundwater. 


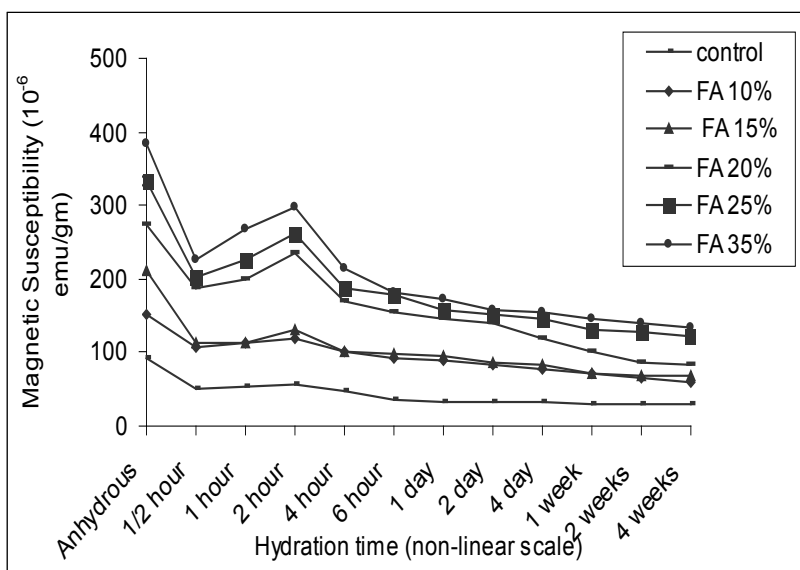

Figure 4. Magnetic susceptibility vs. Different hydration time duration of flyash admixtured cement paste treated with seawater.

During hydration $\mathrm{C}_{3} \mathrm{~A}$ and $\mathrm{C}_{4} \mathrm{AF}$ react with gypsum to form Ettringite. Ettringite is the early formation of hydration products. This can be represented by the following equation[18]

$$
\begin{aligned}
& \begin{array}{l}
C_{3} A \\
\text { Tricalcium } \\
\text { aluminate }
\end{array} \\
& \qquad \begin{array}{c}
3 C \bar{S} H_{2} \\
\text { Gypsum }
\end{array}
\end{aligned}
$$

Tetra calcium Gypsum Water Ettringite Aluminoferrite Aluminoferrite hydrate

For groundwater hydrated cement paste (Fig. 3), the susceptibility values were found to be increasing for first $1 / 2$ hour time duration and reach a maximum value during the first 2 hours. This steep increase can be attributed to the formation of an early aluminoferrite hydrate, which is rich in iron. This iron content increases the susceptibility value. After 2 hours onwards the susceptibility values were found to be decreased. This is because the reaction of $\mathrm{C}_{3} \mathrm{~A}$ and $\mathrm{C}_{4} \mathrm{AF}$ were getting slowdown so the formations of hydration products were less paramagnetic than the reactants. This is an indication that realignment of hydroxyl $\left(\mathrm{OH}^{-}\right)$group was taking place where paramagnetic particles are interlocked. Moreover, according to Mohamed A. Ahmed et al,[7] the $\mathrm{Fe}_{2} \mathrm{O}_{3}$ has a tendency to dissociate and liberate $\mathrm{Fe}$ ion in the form of $\mathrm{Fe}^{2+}$ and $\mathrm{Fe}^{3+}$. This tendency may increase near the solubility limit of $\mathrm{Fe}$ in $\mathrm{C}_{3} \mathrm{~A}$. Initially, the active substitution of $\mathrm{Fe}^{3+}$ for $\mathrm{Al}^{3+}$ in $\mathrm{C}_{3} \mathrm{~A}$ lattices causes a steep increase in susceptibility values. This replacement was confirmed by Majumdar[19] and Schlaudt and Roy[20]. As time advances $\mathrm{C}_{3} \mathrm{~A}$ contain more $\mathrm{Fe}^{2+}$ than $\mathrm{Fe}^{3+}$ and $\mathrm{Fe}^{2+}$ substitutes $\mathrm{Ca}^{2+}$ in $\mathrm{C}_{3} \mathrm{~A}$ lattices.

After 1 week hydration, the susceptibility values were decreasing gradually with hydration time. This was due to the formation of hydration products such as calcium silicate hydrate gel $(\mathrm{C}-\mathrm{S}-\mathrm{H}), \mathrm{Ca}(\mathrm{OH})_{2}$ and hence the cement paste becomes condensed and thickens[21] according to the following equations.

$$
2 \mathrm{C}_{3} \mathrm{~S}+7 \mathrm{H} \rightarrow \mathrm{C}_{3} \mathrm{~S}_{2} \mathrm{H}_{8}+3 \mathrm{CH}
$$

Tricalcium silicate water $\mathrm{C}-\mathrm{S}-\mathrm{H}$ Calcium hydroxide

$$
2 \mathrm{C}_{2} \mathrm{~S}+5 \mathrm{H} \rightarrow \mathrm{C}_{3} \mathrm{~S}_{2} \mathrm{H}_{8}+\mathrm{CH}
$$

The C-S-H gel is one of the major strength rendering components of the hydrated cement and it possesses sparse dispersibility, numerous interior structural effects and coarser particle surfaces. Such characteristics results in decrease the magnetic susceptibility values but increase the strength of cement.

From the graph (Fig. 3), it was observed that groundwater treated Flyash admixtured cement also follows the same fashion as that of the groundwater treated cement paste. It is evident that as the replacement of flyash \% increases, the susceptibility value also gets increased.

Fly ash contains higher amount of silicon and aluminium oxides, they can also accelerate the reaction with hydration of cement, increases the formation rate of aluminoferrite in the early hydration period[22]. Fly ash reacts with calcium hydroxide produced in the hydration of Portland cement. As a consequence extra calcium silicate hydrate $(\mathrm{C}-\mathrm{S}-\mathrm{H})$ gel decreases the magnetic susceptibility values at latter stage. From the graph (Fig. 3) it is evident that as the percentages of replacement of fly ash increase, the susceptibility value also gets increased.

Seawater treated pastes (Fig. 4) also shows the same trend as that of groundwater treated paste (Fig. 3) but difference is susceptibility values are getting decreased. This may attribute to seawater, as it contains more amounts of diamagnetic impurities and decreases the magnetic susceptibility. The bulk magnetic susceptibility shows only an additive character with less paramagnetic nature on adding to diamagnetic impurities in the solid solution made up of seawater.

In addition to fly ash, seawater also accelerates the cement hydration due to the mineral content available in the water. The acceleration depends on the chloride, sodium and calcium ions[10,11]. This effect reduces the thickening time, enhances the hydration reaction and the consecutive strength development. At four weeks compressive strength was slightly decreased when compared to groundwater treated cement. This may be attributed to reduction of $\mathrm{Cl}^{-}, \mathrm{Na}^{+}, \mathrm{Ca}^{2+}$ ions and the fast reaction of $\mathrm{C}_{2} \mathrm{~S}$ with seawater.

\section{Conclusions}

The results can be summarized as follows

1. The magnetic measurement is a good tool to study the chemical reactions of water and fly ash on cement hydration. As the weight percentages of fly ash increases, the susceptibility value also increases. This is due to the fly ash having a higher iron content and presence of more magnetic minerals.

2. The high pozzolanic activity of fly ash increases the magnetic susceptibility of the cement with an increase in percentage of flyash replacement level.

3 . The quantitative value of magnetic susceptibility depends on the quality of water. As seawater contains more diamagnetic impurities, it decreases the magnetic susceptibility values when compared to groundwater treated samples.

Dicalcium silicate water C-S-H Calcium hydroxide 
4. At early stage, the magnetic susceptibility values are high because the Portland cement dissolves, reacts greatly and forms hydration products, which disperses easily. After 2 hours, as the cement gel particles start to condense and thicken, the susceptibility values decreases as compressive strength increases. This trend is same irrespective of all samples when mixed with groundwater and sea water.

5. In the early stages, the reaction of fly ash and seawater accelerates the cement hydration which shortens the setting time and enhances the compressive strength, when compared to groundwater. It is also evident that the mineral content in seawater plays a major role in setting time, compressive strength and magnetic susceptibility.

\section{REFERENCES}

[1] Kourounis, S., Tsivilis S., Tsakiridis PE., Papadimitriou GD., and Tsibouki Z., 2007, Cement and Concrete Research 37, 815-822.

[2] Hong-Sam, K., Sang-Ho L., and Han-Young M., 2007, Construction and Building Materials 21, 1229-1237.

[3] Frank Winnefeld and Lothenbach B., 2010, Cement and concrete Research, 40(8), 1239-1247.

[4] Saika, NJ., Sengupta P.,. Gogoi PK., and Borthakur PC., 2002, Cement and Concrete Research 32, 297-302.

[5] Love, CA., Richardson IG., and Brough AR., 2007, Cement and Concrete Research 37(2), 109-117.

[6] Chaipanich, A., 2007, Current Applied Physics 7, 532-536.

[7] Mohamed Ahmed, A., Mohamed Hassaan Y., Mahrous, S., Mikhail H., and Mohamed El-Desoky M., 1995, Journal of American Ceramic Soceity 78(7), 1958- 1960.
[8] Beata Goluchowska, J., 2001, Journal of Applied Geophysics 48,103-112.

[9] David, C., L. Louis, V. Metz, P. Robion, B. Menendez and C. Kissel, 2005, International Journal of Rock Mechanics and Mining Sciences 42,911-923.

[10] Govindarajan, D., 2001. Ph.D thesis, Annamalai University, Tamilnadu, India.

[11] Barathan, S., D. Govindarajan, G. Sivakumar and K. Raghu, 2006, Indian Journal of Pure and Applied Physics 44, 334-338.

[12] Manu Santhanam, M. Cohen, J. Olek, 2006, Cement and Concrete Research 362132-2137.

[13] Voglis, N., Kakali G., Chaniotaki S., and Tsivilis S., 2005, Cement and Concrete Research 27, 191-196.

[14] Shetty, M.S, 2004, Concrete Technology, S. Chand and Co.Ltd press, New Delhi. pp: 146.

[15] Heyding, RD., Tavlor JB., and Hair ML, 1961, Review of Scientific Instrument. 32(2), 161-163.

[16] Bates, LF., Modern Magnetism, Cambridge University Press. New York. 1961.

[17] Taylor, HWFCement Chemistry, Acadamic Press, Inc, New York, 1960.

[18] Mohamed, Y., Mollah A., Palta, P., Thomas Hess R., Rajan K., Vempati and David Cocke, L., 1995, Cement and Concrete Research 25(3), 671-682.

[19] Majumdar, AJ, 1965, Transition Britian Ceramic Society 64, 105-109.

[20] Schlaudt, CM., and Roy D.M., 1965, Nature 206, 919- 923.

[21] Zhihong, W., Sun L., Hou Y., and Tang, E., 2005, Journal of American Ceramic Society 88(7), 799-1802.

[22] Zongjin, L., and Ding, Z, 2003, Cement and Concrete Research 33, 579-584. 